\title{
Research on improving the quality of life of College Teachers
}

\author{
Zehui Jiang ${ }^{1}$, Jun Zhang ${ }^{2 *}$ \\ ${ }^{1}$ Jiangxi University of Traditional Chinese Medicine, Nanchang, Jiangxi, China; \\ ${ }^{2}$ Department of Cardiovascular Medicine,the 94th Hospital of Chinese People's Liberation \\ Army ,Nanchang, Jiangxi, China
}

Related subjects: Jiangxi University Humanities and social science research project (GL1566)

Keywords: College Teachers; The quality of life

\begin{abstract}
This paper introduces the connotation of quality of life, the factors that influence the quality of life, and puts forward some countermeasures to improve the quality of life of teachers so as to stabilize the teachers' emotions and retain talents.
\end{abstract}

\section{The meaning of quality of life}

Quality of life is based on the social economic, cultural background and value orientation, people's sense of their physical status, psychological function, social ability, and the overall situation of individuals. Quality of life is different from the concept of standard of living, the standard of living is to meet the material and cultural needs of life and consumption of products and services of more and less, the quality of life is to answer life is good or not .The quality of life should be based on the standard of living, but its connotation has greater complexity and universality, and it focuses more on the satisfaction of people's spiritual, cultural and other high-level needs, and the evaluation of their environmental conditions.

\section{The main evaluation of quality of life}

Physical status reflects the physical and activity abilities of individuals, that is, physical function and activity ability, which include: limited activities, limited role function and moderate physical strength

All diseases and injuries bring about psychological changes, but only in varying degrees. These psychological changes are mainly emotional and conscious. Emotional response is an indicator of emotional change, while cognitive function is an indicator of changes in consciousness.

Social function mainly includes social communication and social support. Emphasis on the scope and amount of communication, the full extent of social resources, but did not emphasize the effect and quality. Social support includes emotional support and material support.

The general sense refers to the individual to make their health status and living conditions of the self judgment. The general sense is subjective life quality index evaluation.Subjective evaluation of this general relationship with personal and cultural background and values very close. Including health self assessment and self life evaluation.

Schools attach importance to the quality of life of teachers, and it is of great significance. The improvement of teachers' quality of life not only has a great impact on the completion of school work and the efficiency of teaching and research tasks, but also has a profound impact on the improvement of teachers' mental health. 


\section{The quality of life of College Teachers}

In recent years, it is no news that college teachers have died from overwork. In 2005, two university teachers Jiao Lianwei, Gao Wenhuan died in a short period of 4 days; January 2007, Dean of the Huazhong Normal University Institute of exam, due to excessive physical overdraft, only 53 years old on the end of the short life; in September, deputy director of the Xishuangbanna Vocational and Technical Institute Department of languages, fainted on the podium, never wake up, only 44 years old. A fresh life on this end, people can not help but sigh, sigh, then who should pay for these lives? Research at the Chinese People's Public Security University School of public administration and human resources and education channel of sina organized Chinese occupation stress and mental health survey of nearly 9000 teachers in September 2005. According to the results of the survey, $34.6 \%$ of respondents reflected pressure is very large, $47.6 \%$ of the respondents reflect the pressure is relatively large, the two add up to the investigation of $82.2 \%$, because of the long-term work overload, excessive physical overdraft, Guangdong has 20\% university teachers in various disease states, about $70 \%$ of sub-health state, which $1 / 3$ for severe sub-health.

\section{The way to improve the quality of life of College Teachers}

Teacher as the most direct leader in education, the level of quality of life will also affect the construction of teachers, which affect the whole national education. All along, the treatment of teachers is not good enough, in addition, the pressure of teachers work, the heavy workload after class, so that teachers work quality of life has been at a lower level. Although the treatment of teachers in recent years is constantly improving, but there are still many imperfections and unreasonable. Then, how should the school improve the quality of teachers' work and life so as to arouse the enthusiasm of teachers? Schools are organizations that deliver talents to society and contribute to society. But if we only care about the quality of students and ignore the interests of teachers, the future of our schools will be affected. A teacher is an important part of a school. Only when the school puts the teacher first, the teacher puts the students first. Only when we know the real needs of a teacher in time can we find a good starting point for a good job. Therefore, the interests of teachers are the problems that any school administrator has to consider. In order to be a good school administrator, the interests of teachers should be placed in an important position, so as to arouse the enthusiasm of teachers.

In school management, the economic treatment of teachers should be fully guaranteed, to maintain a reasonable standard of living, to achieve the reward and contribution to adapt, so that the distribution of salaries among teachers is relatively fair. In addition, when teachers are compared with those outside the school, there is a fair basis for the teacher to feel that the amount of compensation or the basis for remuneration. It is particularly important to strengthen the design of the welfare system and to increase the proportion of the welfare sector in the total amount of remuneration.

The work environment is also very important for teachers' growth. The working environment has a direct impact on the quality of teachers' work and life, and it also affects the health of teachers. Therefore, to create a good working environment for teachers, teachers can work at ease and mobilize the enthusiasm of teachers. At present, some schools because of lack of teaching resources, resulting in a high degree of teacher scheduling, some teachers as many as 8 10 classes a day, seriously endangering health. The arrangement of the school hours should be arranged according to the different needs of teachers, so as to meet the individual differences of teachers. At the same time, it is necessary to improve the multimedia installation rate and reduce the teachers' reliance on chalk, 
so as to reduce the damage to the health of teachers. Give students and staff a safe working and learning, healthy living environment is very important, safe. Comfortable, economical and beneficial environment can improve work performance, improve people's willingness to work, reduce and prevent the occurrence of occupation disease.

An excellent manager, in addition to considering the salary and work environment of teachers, must also consider the communication needs of teachers. Schools should create a good atmosphere of interpersonal relationship, so that employees can meet their social ownership requirements in the organization through interpersonal interaction and communication. The school is a place where intellectuals gather, and a good group atmosphere is the basic premise for the peace of mind and the basic guarantee for retaining talents. The school trade union should actively focus on the construction of harmony, unity, friendship and mutual aid organization atmosphere to carry out rich and colorful group activities, make full use of traditional holidays for celebration, send warm activity, to strengthen exchanges and cooperation between the staff, make every employee feel the care and warmth of the organization, improve their sense of belonging and organization cohesion.

Democracy plays an important role in school management. Only a school with democratic management can mobilize the enthusiasm of teachers. Autocratic management can only cause teacher dissatisfaction, non cooperation, and even resistance. The teacher is a special group, he can not buy your account, for the management of teachers depends more on their consciousness and enthusiasm, so the decision to the vital interests of some major, we should pay more attention to the teachers, special the old teacher's thoughts and ideas. Both the old teachers and the young teachers, managers only really listen to teacher's thoughts, with an open mind to learn effective opinions and suggestions from their thoughts, his management will be handy. With good communication, you can reduce the conflict, and strengthen the implementation of the policy system, so as to enhance the staff's sense of identity and satisfaction

\section{Strengthen the management of teachers' rights and create a good atmosphere for Democracy}

Trade unions perform their basic duties according to law, guarantee the equal status of workers in the labor relations, realize their legitimate income, meet the material needs, so as to realize the fairness and justice of labor relations and social relations. The trade union organizations of workers effectively through workers congress or workers' Congress and other forms of active participation in the school management, promote public school, improve the management system, is the foundation of improving the quality of teachers. At the same time, trade unions from the height of social responsibility, in mobilizing and organizing teachers and students to actively participate in education, while monitoring the process of teaching and results of education, to ensure the smooth development and effective operation of education and teaching. Therefore, trade union work is the basic work to improve the quality of teachers' work and life, and the trade union can play its special role in an all-round way.

To sum up, in order to improve the quality of life of college teachers, it needs the joint efforts of society, schools and teachers. Society should give teachers a certain personal space, give teachers enough social care, so that teachers can feel the warmth of society, and they have more power and hope, continue to struggle in education. As a workplace for teachers, schools should create a good working environment for teachers from various aspects, adhere to the management concept of "people first" and care for the mental health and quality of life of teachers. Teachers as the backbone of scientific research construction, entrusted with the glorious mission of motherland education, need learn self-regulation, communicate leadership and colleagues, learn with a good attitude to face the complexity of the work, conside the teaching as their work pleasure. Through the 
improvement of various aspects, the school is conducive to improving the quality of life of teachers, so as to train more useful talents for the construction of the country.

\section{Reference}

[1]. Wang Hong, Wang Yang. On the improvement of the quality of work life of college teacher s.[J] Medical Education Exploration, 2005,4(4):275-277.

[2]. Jia Haiwei, Guo Fenglan. Analysis and Reflection on the quality of College Teachers' work life. [J] Journal of Hebei University Of Science and Technology, 2005,5(4):88-92

[3]. Yang Qingbao, Li Huanyu, Li Jing, Cheng Weifeng. Analysis of the status quo and influencing t he life quality of local university young teachers' factors.[J] sports science and technology, 201 4,35(5):92-93

[4]. Guo Xiaojuan, Han Li, Wei Xiaomeng Influence of emotional movement dialectical dietary inte rvention on life quality of College Teachers in sub health state. [J]Chongqing medicine,2015,44 (28):3980-3982.

[5]. Shang Baochun. Research on the factors affecting physical training of College Teachers in Hena n province. [J]. Journal of Henan Institute of Science and Technology: Social Science Edition, 2011, 31 (2): 39-43. 